\title{
Method for Determination of Root Curvature Radius Using Cone-Beam Computed Tomography Images
}

\author{
Carlos ESTRELA ${ }^{1}$ \\ Mike Reis BUENO² \\ Manoel Damião SOUSA-NETO ${ }^{3}$ \\ Jesus Djalma PÉCORA ${ }^{3}$ \\ ${ }^{1}$ Dental School, Federal University of Goiás, Goiânia, GO, Brazil \\ ${ }^{2}$ Dental School, University of Cuiabá, Cuiabá, MT, Brazil \\ ${ }^{3}$ Dental School of Ribeirão Preto, University of São Paulo, Ribeirão Preto, SP, Brazil
}

\begin{abstract}
This article describes and discusses a method to determine root curvature radius by using cone-beam computed tomography (CBCT). The severity of root canal curvature is essential to select instrument and instrumentation technique. The diagnosis and planning of root canal treatment have traditionally been made based on periapical radiography. However, the higher accuracy of CBCT images to identify anatomic and pathologic alterations compared to panoramic and periapical radiographs has been shown to reduce the incidence of false-negative results. In high-resolution images, the measurement of root curvature radius can be obtained by circumcenter. Based on 3 mathematical points determined with the working tools of Planimp ${ }^{\circledR}$ software, it is possible to calculate root curvature radius in both apical and coronal directions. The CBCT-aided method for determination of root curvature radius presented in this article is easy to perform, reproducible and allows a more reliable and predictable endodontic planning, which reflects directly on a more efficacious preparation of curved root canals.
\end{abstract}

Key Words: curvature radius, cone-beam computed tomography, cleaning and shaping, apical transportation, root canal curvature.

\section{INTRODUCTION}

Conventional endodontic treatment is based on emptying, shaping, disinfecting and filling of the root canal system. Removal of infected pulp tissue improves root canal instrumentation since sanitization is benefited by a more efficient action of irrigants and medications, and space is created for the filling material.

Schilder (1) has emphasized that the root canal should present a flare shape from apical to coronal, preserving the apical foramen and not altering the original canal curvature. Several instrumentation techniques have been developed to make root canal preparation easier and more effective (2-13), especially after the development of nickel-titanium instruments. However, transportation of the apical foramen, creation of ledges, elbows, zips, perforations, and instrument fracture can occur along with loss of working length (2,4-9). Knowledge of the complex tooth internal anatomy and careful planning of endodontic treatment are mandatory to reduce failure rates.

Periapical radiography is an essential resource in endodontic diagnosis. Endodontic planning is related to the identification of different aspects observed in radiographic images, including anatomic complexity, presence of material in the root canal, dental development disturbances, and progression, regression and maintenance of apical periodontitis (AP). However, radiographs are two-dimensional representations of threedimensional structures and certain clinical, morphological and biological features may not be reflected in radiographic changes. 
Depending on morphological variations, surrounding bone density, $\mathrm{x}$-ray angulations and radiographic contrast, radiographic images may be misinterpreted. With the great technological advances of recent years, new imaging modalities have been added to dental radiology as viable diagnostic tools, among which cone beam computed tomography (CBCT), which provides detailed high-resolution images of oral structures. CBCT has been used for several clinical and investigational purposes in Endodontics. The accuracy of CBCT images to identify anatomic and pathologic alterations compared to panoramic and periapical radiographs has been shown to reduce the incidence of false-negative results (14).

Root canal shape can be challenging to the endodontist, especially in teeth with dilacerated roots, which require caution to choose the most indicate endodontic instrument and instrumentation technique. Several studies have determined the curvature of the root canals by the angle and the radius methods $(2,3,6$ $8,10,12,15)$ using periapical radiographic images.

This article describes and discusses a method to determine root curvature radius using CBCT images analyzed by a specific software.

\section{DESCRIPTION OF THE METHOD}

The propose method to determine the curvature radius of curved root canal uses two 6-mm semistraight lines superimposed to the root canal (Fig. 1A-C), the primary line (light gray) being the one that represents the longer continuity of the apical region and the secondary line (dark gray) being the one that represents the middle and cervical thirds. Regardless of the length of the secondary line, only the $6 \mathrm{~mm}$ closest to the primary line is used to measure. The midpoint of each semistraight line is determined. From this spot, two lines perpendicular to the semistraight lines are drawn until they meet at a central point, which is named circumcenter. The distance between the circumcenter and the center of each semistraight line is the radius of the circumference (16), which determines the magnitude of the curve (Fig. 1A-C). The semistraight lines can be shorter, if necessary.

In high-resolution images, such as CBCT scans, the measurement of root curvature radius can be obtained by the circumcenter. Based on 3 mathematical points determined using a software named Planimp ${ }^{\circledR}$
(CDT Informatics, Cuiabá, MT, Brazil), root curvature radius can be calculated in both apical and coronal directions. This method aided by CBCT images (Figs. 2A-D) can benefit the endodontic treatment planning and preparation of curved root canals.

The values of root curvature radius considering the two 6-mm semistraight lines are classified as follows: small radius ( $\mathrm{r} \leq 4 \mathrm{~mm})$ : severe curvature; intermediary radius ( $r>4$ and $r \leq 8 \mathrm{~mm}$ ): moderate curvature; and large radius ( $r>8 \mathrm{~mm})$ : mild curvature.

\section{DISCUSSION}

The present method to determine root curvature radius is easy, reproducible and efficient, particularly when using CBCT images. Knowledge of root curvature radius allows a more accurate planning of root canal instrumentation and minimizes the impact of the anatomic difficulties and limitations of the endodontic instruments. This method permits the maintainance of the curves associated with continuously tapered shapes and prevents structural deformations of the endodontic
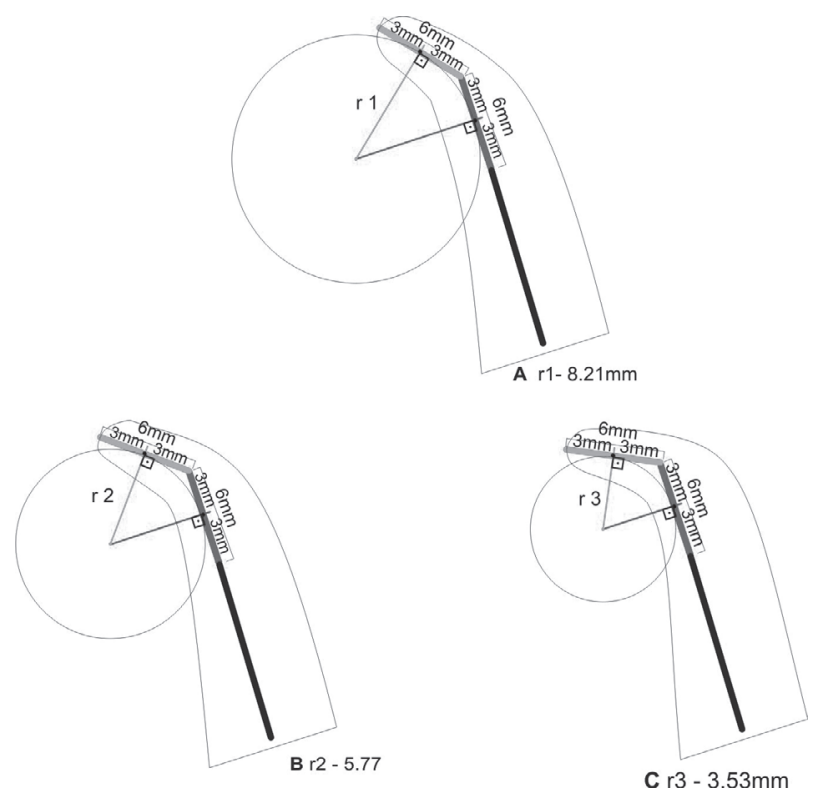

Figure 1. The root curvature radius based on 3 mathematical points can be determined in both apical and coronal directions. Curvature radius considering the two 6-mm semistraight lines are classified as small radius $(\mathrm{r} \leq 4 \mathrm{~mm})$ : severe curvature; intermediary radius ( $r>4$ and $r \leq 8 \mathrm{~mm}$ ): moderate curvature; and large radius $(\mathrm{r}>8 \mathrm{~mm})$ : mild curvature. 
instruments. In this way, disastrous consequences to root canal preparation can be avoided, such as loss of working length, apical transportation, creation of ledges, elbows, zips and perforations, and fracture of instruments.

Some root canal curvature classifications use definitions like apical curve, gradual curve, sickle-shape curve, severe-moderate-straight curve, bayonet curve, dilacerated curve $(5,11)$. Several studies $(2,3,6-$ $8,10,12,15)$ have suggested methods to determine root canal curvature using periapical radiographs. Schneider (12) proposed a method to determine curvature based on the angle that is obtained by two straight lines. The first is parallel to the long axis of the root canal, and the
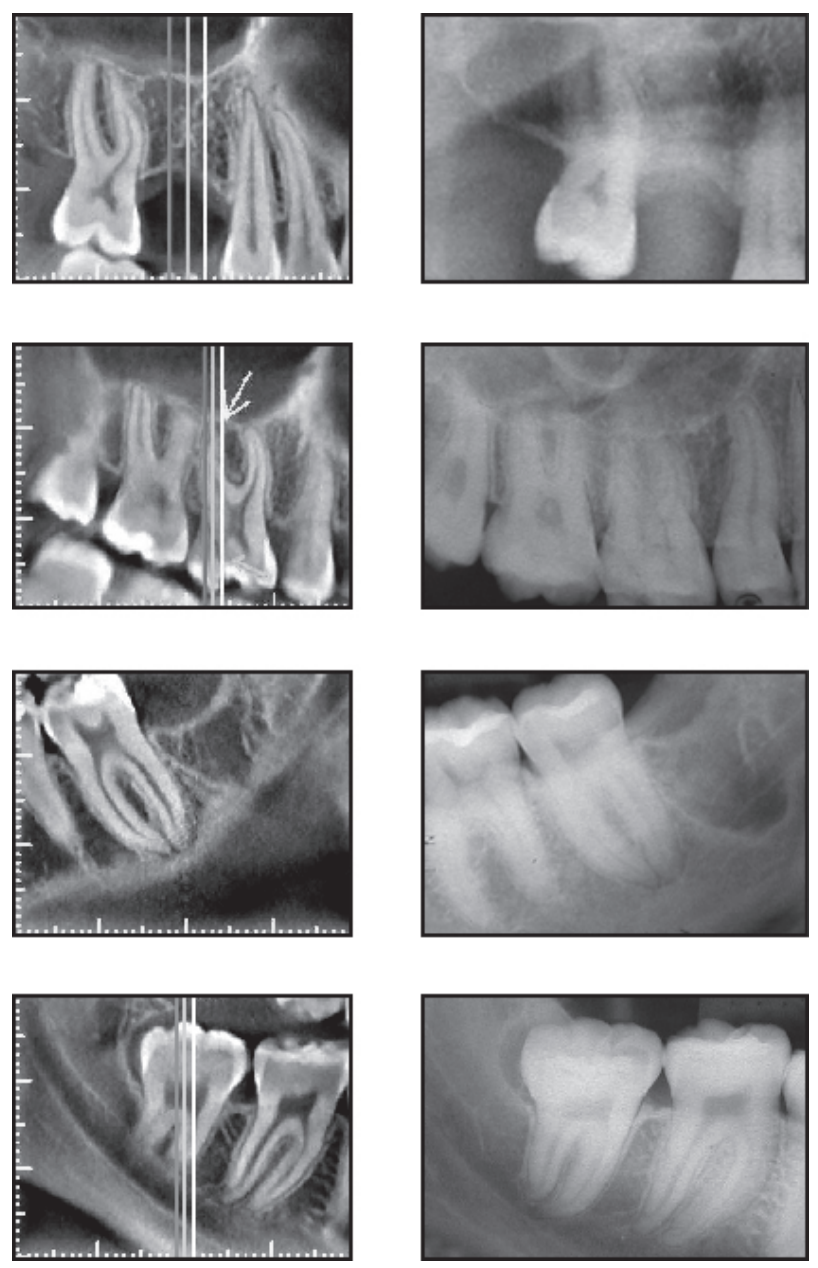

Figure 2. Accuracy of the visual appearance of root canal morphology allows a better determination of root curvature using CBCT images than periapical images. second passes through the apical foramen until intersecting with the first line at the point where the curvature starts. The formed angle $(\alpha)$ was named according to the degree of root canal curvature: straight: 5\%; moderate: $10-20^{\circ}$; and severe: $25-70^{\circ}$. Dobó-Nagy et al. (15) described a mathematically based classification of root canal curvatures on natural human teeth, suggesting a standard description of root canal shapes with the help of differentiated geometrical pattern analysis and computer graphics. In this study, measurements of over 400 roots were conducted on isometric radiographs taken from the clinical view. Measured points of the same radiographs were approximated using fourth degree polynomial functions describing the imaginary axis of canals. This type of classification of root canals is suitable for standardizing test specimens, including natural human teeth, used for testing root forms: I (straight), J (apical curve), C (entirely curved) or S (multicurved). Pruett et al. (10) reported that the effect of the radius of curvature as an independent variable should be considered in studies evaluating root canal instrumentation. Two root canals measured at the same angle in degrees by Schneider's method could have very different radii or abruptness of curvatures. Lopes et al. (6) evaluated the occurrence of apical transportation after root canal instrumentation using K-Flexofiles alone or intercalated with K-Flexofile Golden Mediums. The degree (Schneider's method) and the radius of curvature were recorded before and after instrumentation. There was no significant difference between the techniques. The correlation between the degree and the radius of curvature of the root canal was not consistent, neither existed a relationship between the original radius of curvature and apical transportation. However, determination of root curvature by use of its radius has proved to be an effective method.

It is not easy to observe the standard sample of root canal morphology with the precise visual appearance. By the method described in the present study for determination of curvature radius, it is possible to analyze a specific length of root canal, and it is not necessary the whole canal length. This is an interesting fact becausemore one curvature (e.g.: coronal and/or apical portion) can be found in the same root canal, which will not permit an accurate calculation of radius in the entire root length. Likewise, Lopes et al. (7) reported that in a curved canal with the same radius, it is possible to have arcs (curved segments) with differ- 
ent lengths (angles with different degrees). These differences may influence the intensity of the tensile and compressive stresses induced in the helical shaft of an endodontic instrument, thus altering its resistance to cyclic fatigue. Cunningham and Senia (3) studied the degree and configuration of canal curvature in the mesial roots of 100 mandibular first and second molars. The teeth were radiographed in buccolingual (clinical) and mesiodistal (proximal) directions with \#8 K-files in place. One hundred percent of the specimens had curvature in both views. No correlation was found between the clinical and proximal views regarding the degree of curvature. Secondary curvature, in a direction opposite to that of the main curve, was seen more frequently in the proximal view. In the proximal view, canals had a greater mean curvature than the secondary curvature in $38 \%$ of the cases.

In the present study, root curvature radii considering the two 6-mm semistraight lines were classified as small, intermediary and large, corresponding to severe, moderate and mild root curvatures, respectively (Fig. $1 \mathrm{~A}-\mathrm{C})$, as reported elsewhere $(6,10)$. Root canals with small radius can be associated with a negative impact on instrument or instrumentation technique. Lopes et al. (6) reported that the number of cycles necessary to induce cyclic fatigue fracture in ProTaper F3 instruments used in rotating-bending in canals with the same curvature radius decreases as the length of the arcs increase.

The determination of root canal curvature is unquestionably a key procedure for endodontic planning. However, another aspect that cannot be overlooked before root canal instrumentation is the accurate working length determination $(9,17,18)$. Pécora et al. (9) reported that the instrument-binding technique, though commonly used, is not precise for such purpose. In their study, preflaring of the cervical and middle root canal thirds with rotary instruments provided a significantly more accurate determination of the working length. Orifice openers created a more precise relationship between file size and anatomic diameter.

CBCT provides images of root canal morphology with higher resolution than those obtained with periapical radiography (Figs. 2A-D). Estrela et al. (14) verified the accuracy of CBCT imaging and panoramic and periapical radiographs on detection of apical periodontitis. The use of conventional radiographic images for detection of apical periodontitis should be done with care because of the high possibility of false-negative diagnosis. A great advantage of using CBCT in endodontics refers to its usefulness in aiding in the identification of essential anatomic structures and periapical lesions, and in the differential diagnosis with a highly accurate noninvasive technique. AP was correctly identified in $54.5 \%$ of the cases with periapical radiographs and in $27.8 \%$ of the cases with panoramic radiographs. Minor changes in sensitivity were found for the different tooth groups, except for incisors in panoramic radiographs. CBCT proved to be an accurate diagnostic method.

The CBCT-aided method for determination of root curvature radius presented in this article is easy to perform, reproducible and allows a more reliable and predictable endodontic planning, which reflects directly on a more efficacious preparation of curved root canals.

\section{RESUMO}

O objetivo deste estudo foi discutir um método para obter o raio de curvatura a partir de imagens de tomografias computadorizadas cone beam (CBCT). A severidade da curvatura do canal radicular é essencial para selecionar o instrumento e a técnica de instrumentação. O diagnóstico e o planejamento do tratamento endodôntico tem sido feito com o auxílio da radiografia periapical. Contudo, a precisão da imagem obtida por CBCT para identificar alterações anatômicas e patológicas reduz os resultados falso-negativos. Em imagens com alta qualidade de resolução a mensuração do raio de curvatura pode ser obtida a partir do circuncentro. Baseado em três pontos matemáticos com a ferramenta de trabalho de um software $\left(\right.$ Planimp $\left.^{\circledR}\right)$ pode-se calcular o raio de curvatura em ambas as direções, tanto para frente em sentido apical, como para trás em direção cervical. Este método para se determinar o raio de curvatura auxiliado por imagens de tomografia computadorizada é fácil, reprodutível e favorece o planejamento do tratamento endodôntico o que influencia na eficácia do preparo de canais radiculares curvos.

\section{REFERENCES}

1. Schilder H. Cleaning and shaping the root canal. Dent Clin North Amer 1974;8:269-296.

2. Cimis GM, Boyler TF, Pelleu-Jr GR. Effect of three files studies of canal curvatures in the mesial roots of mandibular molars. J Endod 1988;14:441-444.

3. Cunningham CJ, Senia ES. A three dimensional studies of canal curvatures in the mesial roots of mandibular molars. J Endod 1992;18:294-300.

4. Hülsmann M, Schade M, Schäfers F. A comparative study of root canal preparation with Hero 642 and Quantec SC rotary Ni-Ti instruments. Int Endod J 2001;34:538-546.

5. Ingle JI, Taintor JF. Endodontics. 3rd ed. Philadelphia: Lea \& Febiger; 1985.

6. Lopes HP, Elias CN, Estrela C, Siqueira JF Jr. Assessment of the apical transportation of root canals using the method of 
the curvature radius. Braz Dent J 1998;9:39-45.

7. Lopes HP, Moreira EJL, Elias CN, Almeida RA, Neves MS. Cyclic fatigue of protaper instruments. J Endod 2008;33:5557.

8. Moreira EJL, Lopes HP, Elias CN, Fidel RAS. Flexion rotation fracture of NiTi endodontic instruments. RBO 2002;59:412414.

9. Pécora JD, Capelli A, Guerisoli DMZ, Spanó JCE, Estrela C. Influence of cervical preflaring on apical file size determination. Int Endod J 2005;38:430-435.

10. Pruett JP, Clement DJ, Carnes DL. Cyclic fatigue testing of nickel-titanium endodontic instruments. J Endod 1997;23:7785 .

11. Pucci FM, Reig R. Conductos radiculares. Buenos Aires: Médico-Quirurgica, 1944

12. Schäfer E, Florek H. Efficiency of rotary nickel-titanium K3 instruments compared with stainless steel hand K-Flexo-file. Part 1. Shaping ability in simulated curved canals. Int Endod J 2003;36:199-207.

13. Schneider SW. A comparison of canal preparations in straight and curved root canals. Oral Surg Oral med Oral Pathol
1971;32:271-275.

14. Estrela C, Bueno MR, Leles CR, Azevedo BC, Azevedo JR. Accuracy of computed tomography, panoramic and periapical radiographic for the detection of apical periodontitis. J Endod 2008;34:273-279.

15. Dobó-Nagy C, Szabó J, Szabó J. A mathematically based classification of root canal curvatures on natural human teeth. J Endod 1995; 11:567-560.

16. Boyer CB. A History of Mathematics. 2nd ed. Revised by Merzbach UC. New York: Wiley; 1989.

17. Vanni JR, Santos R, Limongi O, Guerisoli DMZ, Capelli A, Pecora JD. Influence of cervical preflaring on determination of apical file size in maxillary molars: SEM analysis. Braz Dent J 2005;16:181-186.

18. Ibelli GS, Barroso JM, Capelli A, Spanó JC, Pécora JD. Influence of cervical preflaring on apical file size determination in maxillary lateral incisors. Braz Dent $\mathrm{J}$ 2007;18:102-106.

Accepted August 15, 2007 